\title{
Erratum to: Long-lasting permethrin-impregnated clothing: protective efficacy against malaria in hyperendemic foci, and laundering, wearing, and weathering effects on residual bioactivity after worst-case use in the rain forests of French Guiana
}

\author{
Bruno Most ${ }^{1} \cdot$ Vincent Pommier de Santi ${ }^{2}$. Frédéric Pagès ${ }^{2,3} \cdot$ Marie Mura $^{4}$. \\ Waltraud M. Uedelhoven ${ }^{5}$ - Michael K. Faulde ${ }^{6,7}$
}

Published online: 23 May 2017

(C) Springer-Verlag Berlin Heidelberg 2017

Erratum to: Parasitology Research 116(2): 677-684

DOI 10.1007/s00436-016-5333-6

The original version of this article unfortunately contained a mistake. One author's name was incorrect in the HTML version of this article. The correct name is given below:

Vincent Pommier de Santi

The online version of the original article can be found at http://dx.doi.org/ $10.1007 / \mathrm{s} 00436-016-5333-6$

Michael K. Faulde

MichaelFaulde@bundeswehr.org

1 Director Department A, Bundeswehr Medical Office,

Koblenz, Germany

2 French Armed Forces Center for Epidemiology and Public Health, (CESPA), Camp Militaire de Sainte Marthe, Marseille, France

3 Regional Office of the French Institute for Public Health Surveillance (Cire OI, Institut de Veille Sanitaire), Saint-Denis, Réunion, France

4 Institut de Recherche Biomédicale des Armées, Cedex, Brétigny sur Orge, France

5 Bundeswehr Research Institute for Materials, Fuels, and Lubricants, Erding, Germany

6 Department of Medical Entomology/Zoology, Central Institute of the Bundeswehr Medical Service, PO Box 7340,

56065 Koblenz, Germany

7 Institute of Medical Microbiology, Immunology and Parasitology, University Clinics Bonn, 53105 Bonn, Germany 